\title{
EL CARÁCTER CONCRETO DEL CONTROL DE INAPLICABILIDAD POR INCONSTITUCIONALIDAD DE LA LEY EN EL DERECHO CHILENO ${ }^{1}$
}

\section{RODRIGO PICA Flores*}

RESUMEN: El presente trabajo versa acerca de la conceptualización del control concreto de constitucionalidad, su relación con el sistema difuso, su introducción en el sistema concentrado y la necesidad de redefinirlo en función de ese hecho. A continuación se aborda la definición y caracterización de este tipo de control, para posteriormente analizar su introducción en el sistema chileno de jurisdicción constitucional.

PALABRAS CLAVE: Control jurídico de la ley - acción de inaplicabilidad - Derecho procesal constitucional - control concreto.

\section{THE CONCRETE CHARACTER OF THE REGULATION OF INAPPLICABILITY FOR UNCONSTITUTIONALITY OF THE LAW IN THE CHILEAN LEGAL SYSTEM}

ABSTRACT: This work deals with the conceptualization of the concrete constitutional regulations, their connection with the vague system, their introduction in the concentrated system, and their need to redefine them in terms of that fact. Later, a definition is proponed and a characterization of this type of regulation, to later analyze its introduction y the Chilean constitutional jurisdiction.

KEY WORDS: Legal regulation of the law - inapplicability action Procedural Law - concrete regulation

Magíster en Derecho, Profesor de Derecho Constitucional, Universidad Católica del Norte y Universidad Central de Chile. Correo electrónico: rpicaf@yahoo.es

Fecha de recepción: 25 de noviembre de 2009.

Fecha de aprobación: 18 de diciembre de 2009.

1 Artículo elaborado en el marco del proyecto de investigación FONDECYT regular titulado "Sujetos, objeto y decisión en la cuestión de inaplicabilidad: formulación del marco de principios procesales constitucionales que encuadran el control concreto de constitucionalidad de la legislación y la jurisprudencia", No 1090607 , del cual su autor es coinvestigador. 


\section{SUMARIO}

1) Planteamiento del problema. 2) Origen y conceptualización del control concreto de constitucionalidad. (2.1) ¿Cuál es el origen del denominado "control concreto"? (2.2) La introducción del control concreto en el sistema concentrado. (2.3) Hacia una conceptualización actual del control concreto. (2.4) Algunas notas y consecuencias del desarrollo y la profundización del control concreto. 3) La introducción del control concreto en las potestades del $T C$ en el nuevo sistema de jurisdicción constitucional del control de normas. (3.1) Los cambios introducidos al sistema de control de normas. (3.2) La necesidad de delimitar el control concreto de constitucionalidad del control de validez de resoluciones judiciales (3.3) ¿Qué elementos de control concreto tiene el instituto de la inaplicabilidad por inconstitucionalidad de la ley? (3.4) La definición del carácter concreto del control de inaplicabilidad en la doctrina nacional. 4) Conclusiones.

\section{1) Planteamiento Del PRoblema}

El impacto de las reformas constitucionales del año 2005 se ha traducido en variados cambios en el sistema constitucional chileno, entre ellos los relativos al sistema de control de supremacía constitucional.

El traspaso de la competencia para conocer y resolver de la acción de inaplicabilidad de la Corte Suprema al Tribunal Constitucional mediante la gran reforma constitucional contenida en la Ley No 20.050, conjuntamente con las otras atribuciones que se le confieren en dicha ley, ha significado uno de los cambios más importantes a la Constitución. En palabras de Francisco Zúñiga, una "ampliación notable de su competencia y racionalización de sus decisiones y sentencias" ${ }^{2}$, al punto que incluso se ha hablado de un nuevo Tribunal Constitucional, en atención a su integración $\mathrm{y}$ a sus competencias ${ }^{3}$.

En ese marco, con la gran idea matriz de terminar con los enclaves autoritarios en la Carta de $1980^{4}$, y en esta parte, además, con el ánimo

ZúñIga Urbina, Francisco (2006). "Refundación del Tribunal Constitucional", La Semana Juridica, del 19 al 26 de junio, Santiago: LexisNexis. dios sobre las democratizaciones, México: Fondo de Cultura Económica; Garretón, Manuel Antonio (1990). "La posibilidad democrática en Chile", en Democracia contemporánea: Transición y Consolidación, pp. 177-190, Santiago: Editorial Universidad Católica de Chile. 
de perfeccionar y fortalecer las competencias de control de supremacía constitucional, se modificaron sustancialmente tanto la integración como las atribuciones del Tribunal Constitucional.

Así, las sustanciales modificaciones a la acción de inaplicabilidad por inconstitucionalidad de la ley, hoy plasmadas en el numeral $6^{\circ} \mathrm{y}$ en el inciso undécimo del nuevo artículo 93, han dado paso a lo que unánimemente se suele llamar la introducción del control concreto en nuestro sistema, trasladando el juicio desde la formulación abstracta de la ley hacia los efectos de su aplicación, atendido el inequívoco tenor literal del actual numeral $6^{\circ}$ del artículo 93 de la Constitución, con efectos inter partes, paralelo a lo cual se instaura una acción directa de inconstitucionalidad, abstracta y de efectos erga omnes y ex nunc, que tiene como presupuesto a la declaración de inaplicabilidad, en un binomio que no es común en ningún sistema de control concentrado, y que, muy parcialmente, se asimila solo al sistema portugués en algunos aspectos, como la dualidad control concreto y efectos particulares $-\mathrm{a}$ iniciativa de parte- con control abstracto y erga omnes ${ }^{5}$ posterior. De este modo se transforma el sentido constitucional original de dicha fórmula de control represivo de legislación, iniciándose un tránsito de este instituto hacia la configuración de una herramienta procesal de control preventivo (y eventualmente ex post) del ejercicio de la función jurisdiccio$\mathrm{nal}^{6}$, en tanto ella es la aplicadora común de preceptos legales.

Teniendo en cuenta lo expuesto, se asume como un hecho indiscutido el carácter concreto de la cuestión de inaplicabilidad ${ }^{7}$, en tanto el objeto controlado ya no es el precepto legal sino los efectos de su aplicación. De lo escueto y breve de la preceptiva constitucional respectiva surgen interrogantes acerca del contenido y límite de los elementos del control concreto, más aún si no se definió -ni en la Constitución ni en la génesis de sus reformas- qué es lo que debe entenderse por "control concreto de constitucionalidad de preceptos legales" para efectos de la inaplicabilidad,

\footnotetext{
5 Ver a este respecto, Moreira Cardoso da Costa, José Manuel (2002). "Tópicos sobre competencias e integración del Tribunal Constitucional de Portugal", Ius et Praxis, vol. $8, \mathrm{~N}^{\circ} 1$, Universidad de Talca, Chile, disponible en http://www.scielo.cl/scielo. php?pid=S0718-00122002000100017\&script=sci_arttext

6 Cazor Aliste, Kamel; Pica Flores, Rodrigo (2009). "Tribunal Constitucional y control concreto en Chile: ‘evolución hacia un amparo imperfecto?". Revista General de Derecho Constitucional Iustel, No 7, p. 4.

7 Ver, por ejemplo, Ríos Álvarez, Lautaro (2005 a). "Trascendencia de la reforma constitucional en la fisonomía y las atribuciones del Tribunal Constitucional". Estudios Constitucionales, Año 3, Nº. 1, Ediciones Universidad de Talca; Gómez Bernales, Gastón (2005). "La reforma constitucional a la jurisdicción constitucional", en Zúńiga Urbina, Francisco (coordinador). Reforma constitucional, Santiago: LexisNexis; ZúñIga Urbina, Francisco Vega MÉNDEZ, Francisco (2006). "El nuevo recurso de inaplicabilidad por inconstitucionalidad ante el Tribunal Constitucional. Teoría y práctica". Estudios Constitucionales, Ańo 4, N 2; Fermandois V., Arturo (2008). "Inaplicabilidad y control concreto del Tribunal Constitucional: enjuiciando la arbitrariedad en la aplicación de la ley". Actualidad Juridica, $\mathrm{N}^{\circ} 17$.
} 
lo que debe ser comprendido a la luz de la inexistencia de amparo especial en el catálogo de competencias atributivas del artículo 93 de la Constitución, en términos que la justicia constitucional de derechos fundamentales está entregada a los tribunales ordinarios por la vía de los artículos 20 y 21 de la Carta Política ${ }^{8}$, sin perjuicio de otras herramientas como la tutela de derechos fundamentales en materia laboral y el recurso de nulidad en materia penal.

Esta configuración de potestades, control concentrado-concreto sin amparo extraordinario, deviene necesariamente en la necesidad de definir y delimitar el concepto y elementos del control del concreto en el marco de nuestro sistema concentrado, para determinar en qué medida el proceso de inaplicabilidad participa de ellos tras la reforma constitucional de la Ley No 20.050.

Paralelamente, la ya mencionada inexistencia de amparo y la configuración actual de nuestro sistema de control hacen necesario indagar en la delimitación de las potestades de la jurisdicción constitucional y las propias de la jurisdicción común.

Dentro del marco anteriormente expuesto, la reforma constitucional aludida afectó, en diversos sentidos, al estatuto y a la configuración del control de inaplicabilidad por inconstitucionalidad de la ley. Entre otras áreas, la ya aludida concentración de control de normas, sin amparo extraordinario y complementada por la iniciativa judicial para requerir de inaplicabilidad, permite sostener la superación de las clásicas conceptualizaciones de los sistemas difusos y concentrados?

Por otra parte -como ya se mencionara-, se trasladó la preeminencia del juicio de constitucionalidad, desde la formulación de la ley hacia el escrutinio de los efectos que produce su aplicación, al sustituirse del antiguo artículo 80 la frase "precepto legal contrario a la Constitución" proveniente de la Carta de 1925, por la fórmula "precepto legal cuya aplicación en cualquier gestión que se siga ante un tribunal ordinario o especial, resulte contraria a la Constitución".

8 Sobre la carencia de atribuciones de control de resoluciones judiciales, en nuestro sistema de control de constitucionalidad, el TC ha declarado que "por la via de la atribución de la jurisdicción que hace nuestra Constitución Politica en el articulo 76, la exclusividad del ejercicio de la misma, y la regla de la inavocabilidad, además de las normas legales sobre nulidad procesal y recursos de casación contenidas en el Código de Procedimiento Civil y la regla de competencia de la extensión contenida en el Código Orgánico de Tribunales, resulta evidente que de conformidad a la ley es la judicatura ordinaria quien tiene las potestades de control sobre la validez de las actuaciones procesales". Tribunal Constitucional de Chile. Sentencia de 22 de enero de 2009. Rol No 1006-07 "Requerimiento de inaplicabilidad de Eduardo Berríos Novakovic respecto del artículo 96 del Código Tributario" (cons. 11 del voto de rechazo). Disponible en línea en http://www.tribunalconstitucional.cl/index.php/sentencias/view/1090 [Fecha de visita 23 de noviembre de 2009].

9 Ruiz Tagle, Pablo, (1999). "Control constitucional concentrado y difuso: el uso de una dicotomía ruinosa”. Revista de Derecho Público, No 61, pp. 81-95. 
Lo anterior llama a caracterizar, en primer término, a la inaplicabilidad como un control de carácter concentrado y concreto al mismo tiempo. Desentrañar los elementos fundamentales del significado de esta fórmula de control es buena parte de la problemática que se busca abordar en el presente trabajo, desde una perspectiva dogmática y al mismo tiempo jurisprudencial.

Es por ello que, como primera cuestión, cabe preguntar ¿̨ué significa la expresión "control concreto"? sobre todo si, como se verá, no es usual en la doctrina chilena encontrar conceptualizaciones directas y específicas acerca de qué ha de entenderse por control concreto de constitucionalidad, cuya conceptualización comparada no es unívoca.

Dependiendo del contexto en el que se aborde, hay que señalar que el control concreto puede dar lugar a diversas instituciones muy distintas entre sí, aun cuando cabe tener presente que, en una primera aproximación, sería pacífico sostener que el control concreto recae en actos de aplicación de normas a un caso concreto.

En segundo lugar, y aclarado qué cabe entender por control concreto, la segunda pregunta que es necesario responder es ¿en qué consiste el carácter concreto del juicio de inaplicabilidad? tema sobre lo cual el Tribunal Constitucional ha emitido abundante jurisprudencia, pero que en doctrina es uno de los más novedosos, actuales y poco explorados en nuestro medio, aun cuando parezca pacífico.

\section{2) ORIGEN Y CONCEPTUALIZACIÓN DEL CONTROL CONCRETO DE CONSTITUCIONALIDAD}

\section{(2.1) ¿CUÁl ES EL ORIGEN DEL DENOMINADO “CONTROL CONCRETO”?}

Es un lugar común señalar que el denominado "control concreto" tiene sus orígenes en el control difuso del derecho norteamericano, en el cual el conflicto constitucional, para ser resuelto en sede jurisdiccional -suele señalarse-, requiere, en principio, de actos de aplicación en el marco de un proceso jurisdiccional pendiente de resolver, elemento que más adelante se denominará "incidentalidad" en este trabajo.

En el sistema norteamericano, "La justiciabilidad de un caso constitucional no se produce solo por un conflicto entre la ley y la Constitución, es necesario además que exista una parte procesal, a la cual la norma legal le produzca un agravio suficiente y actual, que por la vía jurisdiccional ordinaria pueda obtener reparación en defensa de sus derechos (...) debe existir un hecho específico concreto que demuestre la existencia de un dańo o agravio (injury) directo e inmediato que sufre la persona del demandante, producido por el demandado (relación de causalidad: causation), que puede ser superado o remediado (redress) por una decisión 
favorable del tribunal"10. En función de dichos caracteres, se ha llegado a decir que, en atención a los antecedentes históricos, el concepto de control concreto "se resume en la judicial rewiew norteamericana y (...) se distingue también por la peculiaridad de que cualquier juez puede pronunciarse sobre la aquiescencia constitucional de la ley, de tal suerte que puede decidir incluso, dejar de aplicarla, por estimar que es contraria a la Constitución" 11 . Así, en principio, la noción de control concreto surge hermanada a la de sistema difuso.

Dentro de esta corriente que une y hermana los conceptos de difuso y concreto, en nuestro medio se señala que "cuando se habla de control concreto, se hace referencia a un control en que el contraste normativo entre el respectivo precepto (cuestionado por la incidencia que tiene en la cuestión a resolver) y la Constitución es hecha por el tribunal que conoce del asunto"12. Este planteamiento parte de la base que el control concreto requiere per se de un sistema difuso, y que "la concreción está dada aquí precisamente por el apoderamiento jurisdiccional que el tribunal hace del asunto, tanto desde la perspectiva del razonamiento y decisión relativos a la integración del sistema de fuentes, incluyendo la interpretación de textos normativos, como desde el ángulo de la conexión de los datos tácticos, y su calificación jurídica, con el sistema de fuentes, y todo ello a la luz de los elementos de juicio, de carácter procesal, que los relacionan (como por ejemplo, la aportación de la prueba)"13, visión que -de una forma u otra- también comparte Fermandois, según más adelante se verá.

Por otra parte, la necesidad de un caso litigioso como presupuesto de control permite afirmar que: "La distinción fundamental entre control concreto y abstracto -a su vez- considera las modalidades previstas para activar el procedimiento de control. La primera hipótesis está simbolizada por los sistemas de judicial review, en el cual el control es llevado a cabo por el juez, en el momento de resolver una controversia determinada. El control abstracto permite, en cambio, valorar la conformidad a la Constitución de una norma de ley independientemente de la subsistencia de un contencioso judicial" 14 .

Nogueira Alcalá, Humberto (2003). "Tópicos sobre jurisdicción constitucional y tribunales constitucionales". Revista de Derecho (Valdivia), vol. 14 [citado 22 julio 2009], pp. 43-66. Disponible en http://mingaonline.uach.cl/scielo.php?script=sci_arttext\&pid=S0718$9502003000100003 \& \operatorname{lng}=\mathrm{es} \& \mathrm{nrm}=$ iso

11 Aviña Martínez, Rogelio (2009). "El control previo en el Derecho constitucional local: un visor a la ley de justicia constitucional local para el Estado de Coahuila de Zaragoza", en Gámiz Parral, Máximo N. Astudillo, César Santos Olivo, Isidro de los: Derecho constitucional estatal. Memorias del VI y VII Congresos Estatales de Derecho Constitucional de los estados, México: UNAM, p. 259. Aldunate Lizana, Eduardo (2009). Jurisprudencia constitucional 2006-2008, Santiago: Legal Publishing, p. 11.

13 Aldunate Lizana (2009) 11

14 Rolla, Giancarlo (2005). "Juicio de legitimidad constitucional y tutela de los derechos fun- 
Cabe recordar que en el Derecho norteamericano, el control de constitucionalidad de normas nace en el marco de la actividad jurisdiccional y ligado de manera indisoluble a la adjudicación de derechos en litigios específicos, recayendo ambas tareas, adjudicación de derecho común y jurisdicción constitucional, en el mismo órgano: el juez del fondo.

\section{(2.2) LA INTRODUCCIÓN DEL CONTROL CONCRETO EN EL SISTEMA CONCENTRADO}

En sus orígenes, el sistema concentrado europeo del control de normas aparece totalmente desvinculado de su aplicación a casos específicos, por lo que, hasta mediados de siglo, se podía asumir una conceptualización concentrada-abstracta del sistema europeo, al punto que se señala como lugar común que por parte de los tribunales constitucionales "no se enjuicia hechos concretos", sino solo "la compatibilidad entre dos normas abstractas"15, en contraposición al carácter difuso-concreto del sistema norteamericano.

De esta forma, el sistema difuso aparece ligado indisolublemente a la noción de control concreto y el sistema concentrado aparece ligado a la noción de control abstracto, en términos que el modelo norteamericano "puede definirse como una forma de control difuso, incidental y declarativo, en tanto que la Verfassungerichtsbarkeit, en su concepción originaria, se presenta como un control concentrado, principal y constitutivo"16.

En el sistema europeo de control de constitucionalidad, la configuración del sistema se estructura de una forma radicalmente distinta, pues las labores del juez ordinario de legalidad y del juez constitucional se distinguen conceptual y orgánicamente, al punto que se entregan a órganos distintos de la siguiente manera:

(a) El juzgamiento del fondo, cuestión de legalidad, se entrega al juez de la instancia, integrante del Poder Judicial y

(b) El juicio de legitimidad constitucional, que se entrega a un Tribunal Constitucional autónomo y externo del denominado Poder Judicial.

Las diferencias orgánicas y sistémicas del modelo concentrado europeo con el difuso norteamericano hacen que el control de normas tenga una fisonomía diferenciada en ambos sistemas, ya que en Estados

damentales", Revista Iberoamericana de Derecho Procesal Constitucional, No. 3, pp. 271-291. Disponible en http://www.iidpc.org/revistas [Fecha de visita: 14 de julio de 2009].

15 García de Enterría, Eduardo (1991). La Constitución como norma y el Tribunal Constitucional, Madrid: Civitas, p. 131.

16 Pizzorusso, Alessandro Volpe, G. Sorrentino, F. Moretti, R. (1981). "Garanzie Costituzionalli", en G. Branca (coord.), Comentario della constituzione, Bologna-Roma: ZanicheIli-Il Foro italiano, pp. 7, 24. 
Unidos el tribunal que resuelve el asunto de fondo es el mismo que controla la constitucionalidad de la norma, usualmente en una misma sentencia, labores que en Europa aparecen diferenciadas entre la judicatura ordinaria y la judicatura constitucional, lo que acarrea la necesidad de distinguir las potestades de la judicatura ordinaria y las potestades de la judicatura constitucional, en una experiencia no exenta de problemas y ambigüedades conceptuales que tensionan la institucionalidad ${ }^{17}$.

Hecha esta precisión, es menester señalar que la total abstracción del modelo concentrado comienza a relativizarse muy tempranamente, pues ya la reforma constitucional austríaca de 1929 confiere iniciativa a los jueces para cuestionar la constitucionalidad de normas ante el Tribunal Constitucional, introduciendo en el sistema concentrado el elemento de "incidentalidad" del control de constitucionalidad norteamericano, que está dado porque "el juicio de constitucionalidad no se instaura autónomamente, sino que surge como un incidente en el curso de un procedimiento jurisdiccional que se realiza ante un juez común"18.

De lo antes expuesto se colige que no se está en presencia de un control de carácter directo sobre la ley, sino que se produce por causa directa de un litigio pendiente, que es a su vez el presupuesto básico de su existencia, ya que la inconstitucionalidad "solo puede ser declarada con ocasión de un proceso en el que la decisión del caso dependa de la aplicación de una ley"19. Este elemento de incidentalidad, como se verá, es el primer elemento del control concreto, exigencia que es "inherente a un sistema de control en concreto de inconstitucionalidad" 20 . La reforma al sistema austríaco a fines de los años 20 del siglo pasado será así el germen de la introducción en Europa ${ }^{21}$ del primer elemento que permite reconocer al control concreto.

Ver por ejemplo Mendizábal Allende, Rafael (2005). "La guerra de los jueces: Tribunal Supremo vs Tribunal Constitucional". Revista de Derecho Procesal, No 1, pp. 489-536, y en el caso italiano el texto de Bordalí Salamanca, Andrés (2006). "La tutela de los derechos fundamentales", en Bordalí Salamanca, Andrés (coordinador). Justicia constitucional y derechos fundamentales, Santiago; LexisNexis. Rolla, Giancarlo (2005) 278.

19 Hormazábal Malarée, Hernán (2008). El nuevo Tribunal Constitucional, Santiago: Legal Publishing, p. 7.

Bertelsen, Raúl (1969). Control de constitucionalidad de la ley, Santiago: Editorial Jurídica de Chile, p. 164.

Es necesario precisar que todo control concreto será de carácter incidental, pero no todo control incidental será concreto, en la medida que no concurran lo que más adelante se verá como los otros elementos del mismo. En efecto, la sola existencia de incidentalidad sin los otros elementos es conceptualizada por Rolla, en la ya citada obra, como "la frontera entre los dos modelos", en la medida que según Rubio Llorente "el objeto del litigio es la constitucionalidad de la ley en abstracto, pero el planteamiento de la cuestión arranca de un caso concreto". Rubio Llorente, Francisco (1998). "Tendencias actuales de la Jurisdicción Constitucional en Europa", en Rubio Llorente, Francisco y Jiménez Campo, Javier (coords.): Estudios sobre Jurisdicción Constitucional, Madrid: McGraw-Hill, p. 165. 
Por otra parte, en los sistemas constitucionales alemán e italiano se introduce tras la Segunda Guerra Mundial el control de constitucionalidad de normas, "con elemento de incidentalidad" en el marco de su aplicación a juicios pendientes, en función de la relevancia de ellas en el resultado del juicio, deviniendo así en el actual control concreto, fenómeno a partir del cual el sistema kelseniano inicia una transformación, que rompe el binomio concentrado-abstracto y hace nacer el sistema concentrado-concreto, por el cual "nos encontramos frente a sistemas que de diverso modo combinan elementos propios del sistema americano con los del sistema austríaco" 22 .

Pero tras este fenómeno de separación entre el binomio difuso-concreto, la relativización del binomio concentrado-abstracto y el nacimiento del binomio concentrado-concreto, la conceptualización del control concreto se transforma en un problema, pues ya no se puede hacer en función de su aparente sinonimia con el sistema difuso y la judicial review, lo que exige superarla para poder conceptuar el control concreto en el marco del sistema concentrado.

Así, si ya las categorías de difuso y concentrado como definitorias de un sistema de control pueden considerarse relativizadas, e incluso por algunos superadas ${ }^{23}$, por lo que es un gran error confundir lo concreto con lo difuso y lo abstracto con lo concentrado. Lo anterior significa que el control concreto ya no es sinónimo del modelo norteamericano y el control abstracto no es patrimonio exclusivo del sistema concentrado europeo $^{24}$, al punto que la evolución de los modelos difuso y concentrado "ha conducido a un acercamiento mutuo hasta el punto de que el actual sistema europeo se considera que aúna criterios de los dos modelos históricos" 25 , al fundir lo concreto con lo difuso. Esta evolución no es aislada, produciéndose una "progresiva convergencia entre los elementos de los dos antańo tradicionales sistemas de control de constitucionalidad" 26 .

En primer término, y en este marco, es posible afirmar que el control concreto se señala como lo contrario del control abstracto. En específico,

Pızzorusso, Alessandro, (2005). "Los sistemas de justicia constitucional: de los modelos a la praxis", en él mismo: Justicia, Constitución y Pluralismo, Lima: Palestra, p. 82, en el mismo sentido, Rolla, Giancarlo (2005) 274.

23 Ruiz Tagle, Pablo, (1999) 81.

24 Sobre las tesis que sustentan la existencia de controles abstractos en el sistema difuso norteamericano, ver Vírgala Foruria, Eduardo (2001). "Control abstracto y recurso directo de inconstitucionalidad en los Estados Unidos". Revista Española de Derecho Constitucional, Ańo 21, No 62, pp. 77-124.

25 De Cabo Martín, Carlos (2000). Sobre el concepto de ley, Madrid: Trotta, p. 25.

26 Fernández Segado, Francisco (2002). "La jurisdicción constitucional ante el siglo XXI. (La quiebra de la bipolaridad "sistema americano-sistema europeo-kelseniano" y la búsqueda de nuevas variables explicativas de los sistemas de control de constitucionalidad)". Disponible en http://www.acader.unc.edu.ar/artjurisdiccionconstitucional.pdf [Fecha de visita: 18 de julio de 2009]. 
si bien en Estados Unidos la Judicial review y la Constitutional Adjudication no son definidas bajo los cánones europeos de concreción o abstracción, es posible concluir que originalmente, "de la vinculación que los autores norteamericanos extraen entre el control de constitucionalidad y los requisitos del artículo III de la Constitución puede deducirse que para ellos, en principio, solo existe lo que nosotros entendemos por control concreto" 27 .

\section{(2.3) HaCia UNA CONCEPTUALIZACIÓN ACTUAL DEL CONTROL CONCRETO}

¿Cómo definir entonces el control concreto si no es en función del sistema difuso? En la Europa del sistema concentrado es posible encontrar en la doctrina una primera aproximación al control concreto, de orden estrictamente conceptual y genérico, sin ninguna referencia a un sistema específico, como "la posibilidad reconocida al juez ordinario, cuando tiene que aplicar en un juicio una norma de cuya constitucionalidad tenga dudas-por ejemplo, una ley-, de suspender la resolución sobre el juicio y plantear la cuestión ante el juez constitucional" 28 .

Esta definición primaria permite extraer las siguientes notas:

(a) Forzosamente es la concurrencia de un caso litigioso pendiente de resolver, en el cual la norma puede recibir aplicación en función de un específico supuesto de hecho.

(b) Lo que anterior permite sostener en primer término, que se está en presencia de un control aplicativo, en el cual existe un factor de conexión entre el acto normativo cuya constitucionalidad se cuestiona y la resolución del juicio en el cual se desarrolla la controversia constitucional.

(c) En la medida que el control se desarrolla en el marco de un juicio pendiente, la legitimación activa corresponderá a quien tenga interés o sea parte del mismo.

Además de ello, de la conceptualización de Bon se deducen las primeras diferencias entre el control concreto en sistemas concentrados y difusos, aun cuando en ambos se genera por causa de la aplicación por el juez ordinario de una norma de dudosa constitucionalidad:

27 Vírgala Foruria (2001) 82.

28 Bon, Pierre (1992). "La protección constitucional de los derechos fundamentales: aspectos de Derecho comparado europeo". Revista del Centro de Estudios Constitucionales, No 11, p. 81 . 
(a) Control de constitucionalidad por parte de un órgano diferente del tribunal llamado a resolver el asunto de fondo, de lo que deriva la necesidad de delimitar las competencias de cada uno de ellos.

(b) Suspensión del proceso a quo mientras se resuelve la cuestión de constitucionalidad.

A diferencia de la variante de control concreto norteamericana, en el control concreto de variante europea no es el mismo juez quien resuelve la cuestión de constitucionalidad y la cuestión de fondo, de lo cual deriva que la conceptualización de lo que entendemos por control concreto sería diferente en el derecho estadounidense y en el derecho europeo.

Visto desde la América Hispana, influenciada por la judicial review y al mismo tiempo por el pensamiento kelseniano, el control de constitucionalidad concreto inserto en un sistema concentrado puede ser entendido como aquel "que ejerce el tribunal constitucional a instancias de un juez o tribunal que, a la hora de resolver un determinado litigio, se encuentra en la necesidad de aplicar una ley sobre cuya constitucionalidad se le plantean dudas o existen divergencias de opinión, por lo que eleva la cuestión sobre la constitucionalidad de la ley al Tribunal Constitucional"29.

En el mismo sentido se le define como aquel que "se realiza con motivo de un caso concreto o litigio, en el que además de ventilarse la cuestión de constitucionalidad planteada por alguna de las partes, necesariamente el órgano controlador debe decidir el derecho en disputa por los colitigantes, de ahí, que su determinación por cuanto a la conformidad o no de la norma general con la Constitución, afectara también un interés particular, en este caso el de los contendientes en el juicio ordinario" 30 . Esta conceptualización saca a la luz otra de las grandes características del control concreto, cual es centrarse en derechos e intereses de orden subjetivo, de titularidad específica de una parte de un juicio.

En Chile, la definición genérica del control concreto no es un tema muy explorado ${ }^{31}$. En este sentido, además de lo ya reseńado acerca de la conceptualización de Aldunate, en una vertiente distinta, una de las definiciones elaboradas por la doctrina nacional, centrada en la incidentalidad y el carácter subjetivo de los intereses en juego, señala que este tipo de control se produce cuando "quien promueve la acción o excepción tiene un interés específico en la causa" 32 y se distingue por los siguientes caracteres:

Brage Camazano, Joaquín (2009). La acción de inconstitucionalidad, México: UNAM, p. 79.

30 Aviña Martínez (2009) 259.

31 Más adelante se volverá a analizar el control concreto en la doctrina chilena, pero en referencia al específico carácter concreto de la inaplicabilidad. Nogueira Alcalá (2003) 43 - 66. 
(a) Tiene por objeto inaplicar preceptos legales que, en un caso específi$\mathrm{co}$, se consideran inconstitucionales,

(b) Cautela intereses y derechos de orden subjetivo, mas no objetivos, y

(c) A consecuencia de lo anterior tiene efectos inter partes ${ }^{33}$.

Por otra parte, también es posible hacer una aproximación al control concreto desde la distinción "entre el control de constitucionalidad de la ley y aquel otro control que se lleva a cabo con ocasión de la aplicación de la ley" ", lo que es posible solo a partir de la introducción del "elemento de incidentalidad" en el sistema concentrado, que podrá derivar en un control concreto si además se vincula la decisión de la cuestión de constitucionalidad con las circunstancias, hechos y elementos de un caso específico que se sigue ante el tribunal ordinario. Así, tras la incidentalidad, la concreción "derivará de la relación de prejudicialidad, correspondiente a la relevancia de la cuestión de inconstitucionalidad, que se establece entre los dos juicios" 35 . Es decir, debe establecerse, antes de plantear el juicio de constitucionalidad, la relevancia de la norma a cuestionar, en tanto es aplicable al caso y en tanto es apta para producir un resultado dentro del juicio, lo que en el marco italiano y español se realiza ante el juez a quo, que es el legitimado activo para plantear la cuestión ante el Tribunal Constitucional. Solo una vez que en dicha discusión, denominada prejudicial ya que se realiza ante el tribunal a quo y antes de plantear la cuestión, se establece la relevancia de la norma cuestionada, se podrá proceder a realizar un control concreto ${ }^{36}$.

Este "juicio de relevancia" 37 es, después de la incidentalidad, el segundo elemento del control concreto y de la interoperatividad de ambos

Nogueira Alcalá, Humberto (2002). "La reforma constitucional a la jurisdicción constitucional: del doble control concentrado de constitucionalidad a la concentración del control en el Tribunal Constitucional". Ius et Praxis, Ańo 8, $\mathrm{N}^{\circ} 1$, pp. 337-370. Disponible en http://www.scielo.cl/scielo.php?pid=S0718-00122002000100019\&script=sci_arttext [Fecha de visita: 22 de julio de 2009].

Fernández Segado (2002).

FernándeZ Segado (2002).

En el sistema italiano ello es resuelto por el juez a quo mediante un auto motivado después de oír a las partes, por el cual declarará la relevancia de la norma cuestionada y planteará la cuestión de constitucionalidad.

El juicio de relevancia puede ser definido, en el marco del derecho constitucional italiano, como el examen de "la 'aplicación directa' que efectúe cualquier juez de una disposición o norma constitucional en el marco de la actividad de búsqueda de la norma a aplicar al caso del que está conociendo, cuando el juez deduzca de ahí la derogación (o, de cualquier forma, la no aplicabilidad) de una disposición o norma legislativa ordinaria" por pugnar con la Constitución. Przzorusso, Alessandro (2006). "La justicia constitucional italiana, entre modelo difuso y modelo concreto", en Requejo Pagés, Juan Luis (coordinador): Fundamentos, cuadernos monográficos de Teoria del Estado, Derecho Público e Historia constitucional, $\mathrm{N}^{\circ} 4$ de la serie: La rebelión de las Leyes: Demos y nomos: la agonía de la justicia constitucional", Oviedo: Junta General del Principado de Asturias, p. 251. 
deriva el que denominaremos tercer elemento distintivo del control concreto, constituido por la doble función de la norma cuestionada, en tanto objeto de control:

(a) Por una parte, el objeto controlado cumple una función específica respecto del caso concreto ya que en él "tal norma constituye el objeto del control de constitucionalidad" 38 ... y

(b) ... respecto del proceso constitucional, "es tal norma la que ha de ser aplicada en orden a la resolución del caso, lo que vincula la decisión del Tribunal Constitucional a un concreto caso en cuyo ámbito la norma controlada habla de encontrar aplicación"39.

A partir de esta doble relación de interdependencia entre el caso y el objeto de control surge que el control concreto tiene como elemento necesario la constatación de que caso específico seguido ante el tribunal ordinario vincula al Tribunal Constitucional, en tanto es el marco y el contexto decisional en el cual se plantea la cuestión y en el cual tendrá efecto su sentencia, los cuales deben ser ponderados en ella, sin lo cual estaremos en presencia de un control de carácter abstracto, aunque dotado del elemento incidental.

Así, se puede señalar que estamos en presencia de un control concreto cuando son reconocibles de manera conjunta los siguientes caracteres primarios:

(a) El elemento de incidentalidad ya reseñado.

(b) Aptitud relevante del objeto controlado -norma o acto de aplicación-, en tanto su concurrencia genera un resultado específico. El juicio de constitucionalidad incidirá en un proceso en el que se ventilan intereses de carácter eminentemente privado $-\mathrm{o}$ de titularidad estricta de las partes del proceso-, es decir, derechos subjetivos o intereses legítimos de las partes, dotados de un elemento constitucional relevante o a lo menos determinados por él, a partir del cual se deriva la cuestión de constitucionalidad ${ }^{40}$.

(c) La doble función del objeto de control, en tanto es el marco decisional en el cual ha de tener efecto la sentencia de control de constitucionalidad y, al mismo tiempo, pasa a ser parte misma del parámetro de control, pues para ponderar los efectos de la aplicación en el "juicio de relevancia”, el conflicto y los caracteres del juicio a quo deben

38 Pizzorusso (2006) 251

39 Pizzorusso (2006) 251.

40 En este sentido, el derecho subjetivo dotado de elemento constitucional relevante será usualmente un derecho fundamental, de titularidad de una de las partes del juicio o, a lo menos, un interés legítimo de fuente constitucional. 
ser examinados por el órgano de jurisdicción constitucional al resolver la cuestión planteada.

De todo ello, se debe destacar un desplazamiento de los intereses en juego en el control de normas, pues si en los controles abstractos los intereses en juego son generales y de carácter público, en el control concreto el elemento subjetivo del interés constitucional en cuestión hace emerger una clara connotación de interés privado, en la medida que el proceso puede ser entre particulares o entre particulares y un órgano estatal y se referirá generalmente a situaciones jurídicas disponibles y sin eficacia general.

Tras la conceptualización de los elementos mínimos del control concreto en sentido amplio, cabe entonces establecer un concepto del mismo, que reúna los caracteres expresados y que permita comprender la introducción del control concreto en sistemas jurídicos dotados de Tribunal Constitucional ajeno al Poder Judicial, bajo el modelo kelseniano y sus evoluciones tras la segunda posguerra.

En el sentido antes expresado, no es raro encontrar en un autor italiano una definición que reúna dichos elementos y sistematice el significado de la expresión "control concreto de constitucionalidad", pues en dicho sistema constitucional se pasa de la incidentalidad austríaca al control concreto que hoy conocemos en lo que usualmente se denomina sistema concentrado. En dicho contexto normativo, Pizzorusso, una de las grandes autoridades en la materia, señala que el control concreto de constitucionalidad

"en contraposición a "abstracto", es un control que se ejerce en función de la aplicación que la disposición o norma de cuya constitucionalidad se duda debe recibir o ha recibido respecto de un supuesto de hecho determinado, ya sea porque la realización del control corresponde al mismo juez que debe resolver dicho juicio, ya sea porque corresponde a un juez diferente cuya específica competencia se atribuye como derogación de la del juez "ordinario" y que se presenta, por ello, como un juez "especial". En el primer caso, evidentemente, el control es tanto difuso como concreto, mientras que en el segundo es concentrado pero no necesariamente abstracto" 41 .

Dentro de los caracteres distintivos del control concreto, de la llamada "doble relación" deriva de manera inevitable que una "norma" no es solo un texto de carácter estrictamente genérico e impersonal, sancionado por el poder estatal como una prescripción de conducta, sino que, para 
ser considerado tal, requiere de interpretación y actos de aplicación que la coloquen en movimiento y la doten de imperio para poder surtir algún efecto jurídico, tras lo cual se podrá determinar su significancia y sentido en un caso concreto, todo lo cual pasa a ser parte del objeto controlado en la medida que es menester asumir que "el legislador no es un ejecutor de la Constitución, sino un poder que actúa libremente en el marco de esta y esta libre actuación requiere en muchos casos (aunque no, claro es, en todos) que el enunciado de y su preceptos constitucionales permita un ancho haz de interpretaciones diversas. No de interpretaciones jurídicas, sino de interpretaciones políticas, es decir, de maneras diversas de entender el texto constitucional cuyos enunciados han de construirse, por tanto, con conceptos de valor de un alto grado de abstracción" ${ }^{2}$, sin los cuales el texto de la norma legal no puede ser comprendido ni mucho menos aplicado.

Es por todo lo expresado que el control concreto, en tanto control de aplicación, forzosamente ha de ser control de interpretaciones, ya que toda norma debe ser interpretada para determinar su sentido y sus efec$\operatorname{tos}^{43}$.

A título ilustrativo, cabe señalar que siguiendo a la doctrina comparada, las normas deben ser debidamente distinguidas las disposiciones de las normas:

"Serían la resultante de un proceso hermenéutico de la disposición que puede conducir a extraer varias normas de una sola disposición, mientras que las disposiciones constituirían la expresión formalizada de la voluntad del órgano del que emana un determinado acto jurídico; dicho de otro modo, y siguiendo el concepto kelseniano, la norma sería el significado de un acto, lo que revela meridianamente que, a la inversa de la disposición, la norma no es una cosa, sino un sentido" ${ }^{44}$.

Por otra parte, del elemento de relevancia deriva que el órgano jurisdiccional llamado a aplicar la norma cuya constitucionalidad se cuestiona, necesariamente debe decidir sobre el derecho de las partes en dicho juicio y dentro de las hipótesis de aplicación de la norma controvertida, de lo que deriva como condictio sine qua non la necesidad de formular el juicio de relevancia, en términos de producir su

Rubio Llorente, Francisco (1997). "La interpretación constitucional", en él mismo: La Forma del Poder, estudios sobre la Constitución, Madrid: Centro de Estudios Políticos y Constitucionales, p. 576.

43 Este planteamiento es confirmado en las conceptualizaciones de control concreto que hacen Gastón Gómez y Eduardo Aldunate, citadas en el presente trabajo.

44 Fernández Segado (2002). De aceptarse esta distinción, el control de normas tiene elementos de concreción en la medida que el objeto controlado es un acto de aplicación y el control de disposiciones sería un control netamente abstracto. 
aplicación un resultado específico distinto del que ocurriría en caso de inaplicarla. Es decir, debe evaluarse la conexión de la eventual inconstitucionalidad que se plantea con los supuestos de hecho que motivan la aplicación de la norma cuestionada y sus efectos en el caso concreto, ello porque "la relevancia de la cuestión de inconstitucionalidad depende de la aplicabilidad de la disposición o norma de cuya constitucionalidad se duda a los hechos de la causa pendiente en el juicio a quo" 45 .

Y una vez constatada la concurrencia de los elementos mínimos del control concreto, existen elementos específicos, que son aquellos que dependerán de la configuración del modelo. Sin pretender agotar su enumeración, es posible señalar los siguientes:

(a) La realización del control puede corresponder al mismo juez que debe resolver dicho juicio (modelo norteamericano) o bien puede corresponder a un juez diferente (generalmente un tribunal constitucional propio del modelo concentrado europeo), lo que en el segundo caso acarrea la diferenciación de la labor jurisdiccional en la resolución del fondo de la causa y la resolución del proceso de control de constitucionalidad.

(b) Este control puede realizarse después de terminado el proceso (como por ejemplo el amparo extraordinario en Espańa), o bien deberá efectuarse antes del término del mismo (es el caso de la acción de inaplicabilidad en Chile, que exige que el proceso se encuentre pendiente).

(c) Su fundamento particular y casuístico aconseja -por motivos de coherencia- que sus efectos sean de carácter inter partes en la medida que está estrechamente vinculado al examen del caso concreto, sin perjuicio de que no siempre es así (por ejemplo, el sistema italiano, de control concreto y erga omnes, en cuyo caso la distinción entre normas y disposiciones puede tener especial relevancia. Otra excepción es el caso norteamericano, en el cual, a pesar de los efectos particulares, por la vía del stare decissis la sentencia de inconstitucionalidad finalmente puede llegar a tener efectos generales, "en la misma medida que cualquier decisión jurisprudencial que concurra en la producción del Common law"46). 


\section{(2.4) Algunas notas y CONSECUENCias DEL DESARRollo Y LA PROFUNDIZACIÓN DEL CONTROL CONCRETO}

Por motivos de ilustración y como precisiones para el análisis del carácter concreto del control de inaplicabilidad por inconstitucional, se formulan las siguientes precisiones:

El control concreto, por su carácter incidental y centrado en la tutela de intereses subjetivos y de orden privado, aleja a la justicia constitucional de los conflictos entre órganos políticos y la acerca a la resolución de procesos entre privados, en la medida "despolitiza el ejercicio de la jurisdicción constitucional, ya que este procedimiento es iniciado por el juez ordinario -no por ningún actor político- y se centra en la aplicación práctica de la Constitución y de la Ley, lo que aleja al Alto Tribunal del debate ideológico" 47 propio de los conflictos entre los poderes políticos colegisladores, que se traducen en normas contrarias a la Constitución sometidas a controles abstractos.

Por otra parte, en tanto el control concreto puede extenderse -como se verá- al examen de interpretaciones y eventualmente de actos de aplicación, hoy los tribunales constitucionales no son principalmente garantes de la Constitución contra el legislador, sino más bien se erigen como intérpretes de esta que, mediante la presunción de constitucionalidad y el respeto del principio democrático, hacen surgir el fenómeno de la sentencias atípicas ${ }^{48}$, que en la jurisprudencia del Tribunal Constitucional chileno ${ }^{49}$ aparecen de manera frecuente.

Además de ello, este rol de intérpretes de la Constitución para el caso concreto, deja de ser monopolio exclusivo de los tribunales constitucionales y se irradia a todos los tribunales al conferirse legitimación activa a los jueces ordinarios para requerir de inconstitucionalidad, en una verdadera desconcentración del modelo europeo, ya que "el juez o tribunal

47 Troncoso, Antonio (2001). "Las sentencias básicas del Tribunal Constitucional". Revista Española de Derecho Constitucional, Año 21, No 61, p. 388.

48 Ver, por ejemplo, Zapata Larraín, Patricio (2006). "Las sentencias atípicas en la jurisprudencia del Tribunal Constitucional chileno". Estudios constitucionales, Año 4, No 2, pp. $175-187$.

49 En efecto, en el caso del Tribunal Constitucional de Chile, cabe señalar que dentro de su abundante jurisprudencia ha razonado que "dentro del criterio de interpretación conforme a la Constitución, el respeto hacia las labores que desarrollan tanto el legislador al elaborar las normas de rango legislativo como la judicatura al aplicarlas, obliga al Tribunal Constitucional, en su función de contralor de la constitucionalidad de la ley, a buscar, al menos, alguna interpretación del precepto cuestionado que permita armonizarlo con la Carta Fundamental, y solo en el evento de no ser ello posible, declarar su inconstitucionalidad, criterio que ha sido seguido en las sentencias roles $29,38,304,368,420,460$ y 681 , entre otras". Tribunal Constitucional DE Chile. Sentencia de 13 de mayo de 2008. Rol No 993-07 "Requerimiento de inaplicabilidad presentado por Paul Morrison Cristi, respecto del artículo $4^{\circ}$ de la Ley $\mathrm{N}^{\circ} 20.000^{\prime \prime}$, considerando 5. Disponible en http://www.tribunalconstitucional.cl/index.php/sentencias/ view/934 [Fecha de visita 23 de noviembre de 2009]. 
ordinario que aplica la ley al caso concreto verifica su adecuación a la Ley Suprema no solo cuando decide plantear la cuestión de inconstitucionalidad, sino obviamente también cuando se niega a ello conservándola para sí como parte integrante del ordenamiento" 50 , en un verdadero acto de interpretación constitucional acerca del alcance del texto constitucional para determinar si el precepto legal cuestionado se ajusta a ella o no, fenómeno que en Chile, en cierta medida, ha tenido su reciente punto de partida en las reformas constitucionales del año 2005 que, como se sabe, confirieron legitimidad activa al juez de la causa para requerir de inaplicabilidad.

La introducción del control concreto ha significado una expansión significativa de la supremacía constitucional, en el marco de la constitucionalización de todas las ramas del Derecho y en particular una eficaz herramienta de justicia de los derechos fundamentales entre particulares (eficacia horizontal ${ }^{51}$ ). Al mismo tiempo, se observa una verdadera relativización del carácter puramente privatista de las relaciones jurídicas entre particulares, al punto que "el control concreto de las normas puede conducir a que el Derecho Privado vigente sea objeto de control de constitucionalidad en su aplicación. Así puede el Tribunal Constitucional ejercer su influencia sobre el Derecho Privado vigente y adecuar este a los derechos fundamentales" 52 , lo que significa en sí una expansión de la efectividad de la supremacía constitucional.

Es necesario reparar que dentro del muy amplio género de lo que llamamos control concreto, caben dentro de él institutos muy distintos entre sí, pues en la medida que se cumplen sus caracteres mínimos, caben dentro de él especies tan diversas como el amparo español, la inaplicabilidad chilena, el control incidental italiano y la judicial review norteamericana, entre otros. Por ejemplo, en el caso norteamericano, como ya se viera, juzgar la causa de fondo y juzgar la constitucionalidad de la norma aplicada se confunde, e incluso se hace en una misma sentencia, por un mismo acto y sin distinguir los dos temas. Por otra parte, el amparo español apunta a la validez constitucional del acto de aplicación puro, sin examinar la constitucionalidad de la norma habilitante ${ }^{53}$ y sin resolver -al menos de manera

50 Carrillo, Marc (2001). "La jurisdicción constitucional espańola y el caso chileno". Revista de Derecho (Valdivia), Vol. 12, No 1 pp. 75-89. Disponible en http://mingaonline.uach.cl/ scielo.php?script=sci_arttext\&pid=S0718-9502001000100005\&lng $=e s \& n r m=i s o$ [Fecha de visita: 30 julio 2009].

51 De Vega García, Pedro (2005). "La eficacia frente a particulares de los Derechos Fundamentales (La problemática de la Drittwirkung der Grundrechte)", en Luis Aguiar de Luque (coordinador): Constitución, estado de las autonomias y justicia constitucional, libro de homenaje al profesor Gumersindo Trujillo, Valencia: Tirant lo Blanch, pp. 801-822. de Derecho Constitucional, Año 22, No 66, p. 77.

53 Salvo que de oficio el Tribunal Constitucional plantee la denominada auto cuestión. 
directa- el fondo del asunto, ordenando al tribunal a quo que resuelva de conformidad a la Constitución y, finalmente, la inaplicabilidad chilena tiene por objetivo prevenir la aplicación de una norma en la medida que produzca futuros resultados inconstitucionales en la adjudicación del derecho de las parte de un juicio pendiente, con la precisión de la expresa voluntad del constituyente en orden a no establecer un amparo constitucional ex post, dejando sin posibilidad de control por esta vía a actos de aplicación pretéritos y, al mismo tiempo, ya agotados.

Como ya se señalara anteriormente, según la configuración de cada sistema, la introducción del control concreto en sistemas concentrados trae ciertamente el riesgo de tensión y problemas competenciales en los puntos de contacto entre la judicatura ordinaria y el Tribunal Constitucional, según sea la configuración de la jurisdicción constitucional y sus puntos de contacto con la jurisdicción común. Caso típico de conflicto de este tipo es el de España, a través del amparo en contra de sentencias, a propósito del cual se ha seńalado que: "A una relación de concurrencia entre Tribunal Constitucional y Tribunales ordinarios solo puede llegarse en los países en que el Tribunal Constitucional decide recursos de amparo contra sentencias judiciales en última instancia. Además de Alemania también España, por ejemplo, dispone de recurso de amparo contra sentencias. En ambos Estados esto ha conducido a una continua y creciente sobrecarga de año en año del Tribunal Constitucional y a algunas relaciones problemáticas entre Tribunal Constitucional y Tribunales ordinarios" ${ }^{\prime 4}$, realidad que en nuestro país no existe y sin perjuicio de lo cual, sin necesidad de amparo, pueden darse focos de tensión entre los tribunales supremos y el Tribunal Constitucional en el marco del control concreto, como ya se dijera, en caso como el de Italia, en el desenvolvimiento del control concreto de normas, con eficacia erga omnes ${ }^{55}$.

\section{3) LA INTRODUCCIÓN DEL CONTROL CONCRETO EN LAS POTESTA- DES DEL TC EN EL NUEVO SISTEMA CHILENO DE JURISDICCIÓN CONSTITUCIONAL DEL CONTROL DE NORMAS}

\section{(3.1) Los CAMBios INTROdUCidos AL SISTEMA DE CONTROL DE NORMAS}

Como antecedente previo y marco conceptual del tema en análisis, debe reiterarse que la gran reforma del año 2005 dejó de lado el antiguo modelo chileno de control concentrado "dual", como lo conceptuara

Esta situación se encuentra brevemente enunciada y descrita en el ya citado trabajo de BoRdalí Salamanca (2006). 
Zúñiga, o "compartido", y hemos pasado a un modelo concentrado propiamente tal, dentro del que coexisten controles preventivos obligatorios, controles preventivos facultativos-contenciosos, que son los que ya existían antes de la reforma, con los nuevos controles ex post, concretos y de efectos inter partes (el nuevo recurso de inaplicabilidad, que hace su esperado arribo al Tribunal, estrenando la introducción de la legitimación activa del tribunal que conoce de la causa en la que se origina), y con controles abstractos y de efectos erga omnes (la nueva cuestión de inconstitucionalidad, toda una innovación en nuestro derecho), además del control de los autos acordados dictados por los tribunales superiores, que hasta ese momento carecían de controles de esta especie, todo ello en manos del que el profesor Lautaro Ríos ha denominado el Nuevo Tribunal Constitucional.

Así, el control de constitucionalidad de la ley quedó concentrado única, exclusiva y excluyentemente en el Tribunal Constitucional, quedando a los tribunales ordinarios con competencia para ello solo la tutela constitucional de derechos fundamentales por vía de las acciones de amparo y de protección ${ }^{56}$, que se basan fundamentalmente en infracciones a la ley o a la interdicción de la arbitrariedad que tienen como efecto la violación de derechos fundamentales.

Es posible señalar, como notas distintivas del sistema chileno de control concreto, las siguientes:

(a) La existencia del control concreto configurado como control de normas -no como amparo extraordinario-, con la justicia de derechos fundamentales en la órbita de los tribunales ordinarios,

(b) La conceptualización de la inaplicabilidad como control previo al agotamiento de aplicación del precepto impugnado,

(c) La inexistencia de amparo extraordinario respecto de procesos concluidos,

(d) El efecto inter partes de la sentencia de inaplicabilidad.

\section{(3.2) LA NECESIDAD DE DELIMITAR EL CONTROL CONCRETO DE CONSTITUCIONALIDAD DEL CONTROL DE VALIDEZ DE RESOLU- CIONES JUDICIALES}

A pesar del reforzamiento de la función de control de normas, se reitera una carencia en la competencia atributiva del Tribunal Constitucional, para conocer de las acciones de amparo extraordinario y para revisar

\footnotetext{
56 Ello sin perjuicio de otras tutelas de derechos fundamentales ante los tribunales ordinarios que ha establecido el legislador, como el recurso de nulidad, el amparo legal ante el juez de garantías o la acción especial de tutela de derechos fundamentales en materia laboral.
} 
resoluciones judiciales, ya que -como se viera- en nuestro sistema la jurisdicción constitucional de amparo corresponde solo a los tribunales ordinarios, sin perjuicio de la evolución de que el control concreto en Chile presenta como gran desafío el establecimiento claro de la delimitación entre las potestades de la jurisdicción constitucional y la jurisdicción común, tema del cual poco se ha escrito ${ }^{57} \mathrm{y}$ del cual habrá que esperar-más allá de las nacientes líneas jurisprudenciales-el desarrollo de la evolución jurisprudencial de la inaplicabilidad hacia el amparo imperfecto ${ }^{58}$.

Precisado lo ya expuesto, y a pesar de constatarse en nuestro sistema la inexistencia de los riesgos de tensión institucional propios del amparo extraordinario -como en el caso espańol, por ejemplo-, quedan interrogantes pendientes acerca de la poco clara delimitación entre las potestades de control concreto y las potestades de revisión de resoluciones de la judicatura ordinaria, que han sido abordadas de manera incipiente por la doctrina nacional ${ }^{59}$ y por la jurisprudencia del $\mathrm{TC}^{60}$, sin que sea un tema pacífico ni mucho menos consensuado. Por ejemplo, y en un sentido diverso a la jurisprudencia citada, se encuentra la ya citada postura de $\mathrm{Al}$ dunate, que llega a señalar que "al Tribunal Constitucional no se le da jurisdicción para conocer 'en concreto' del asunto en que incide la aplicación del precepto" 61 , a pesar de haber señalado en otro trabajo, anterior, que por la vía de la inaplicabilidad el Tribunal Constitucional "ya no se trata

Ver en este sentido el trabajo de Núñez Poblete, Manuel Antonio (2008). "El control de la igualdad en la aplicación de la ley como factor de expansión del control concreto de constitucionalidad de las leyes", en AA. VV.: Sentencias destacadas 2007, Santiago: Instituto Libertad y Desarrollo.

58 Cazor / Pica (2009).

59 Núñez Poblete (2008), Bordalí Salamanca (2006) y Aldunate Lizana (2009). Además Aldunate Lizana, Eduardo (2007). "La reforma constitucional del año 2005 desde la teoría del Derecho y la teoría de la Constitución". Revista de Derecho Público No 69, tomo I, pp. 35-57.

60 El propio Tribunal Constitucional ha razonado que el examen de control concreto de inaplicabilidad "solo puede determinarse, a la luz de los antecedentes que proporciona la gestión en que el precepto legal cuestionado puede aplicarse, como quiera que se trata de un examen concreto de constitucionalidad" (cons. 4), sin que ello implique dar por acreditados hechos litigiosos ni ponderar la prueba rendida en el tribunal a quo, como ya se mencionara anteriormente, en términos tales que "si bien incumbe a los jueces de la instancia, al resolver el asunto sometido a su conocimiento, interpretar los preceptos que lo regulan, la magistratura constitucional no puede prescindir -para calificar los efectos constitucionales de su aplicación- de la estimación de su sentido y alcance, máxime si de la supremacía constitucional deriva la preferencia, entre las posibles que se contradigan, de una interpretación de la norma legal que se ajuste a la Ley Fundamental". Tribunal. Constitucional de Chile. Sentencia de 10 de marzo de 2009. Rol No 1202-08 "Requerimiento de inaplicabilidad de Hinrichsen Trading S.A. respecto del artículo 45, incisos primero y segundo, del Título IV "De la Declaración de Quiebra", del Código de Comercio, y del artículo 26, inciso segundo, del Decreto Ley $N^{\circ} 3.475$, Ley de Timbres y Estampillas", considenrando 9. Disponible en http://www.tribunalconstitucional.cl/index.php/sentencias/view/1106 [Fecha de visita: 23 de noviembre de 2009]. 
solo de un órgano que, en el campo del control de constitucionalidad, realiza un control a preceptos, sino que también a la actividad jurisdiccional. De lo contrario no se entiende como [sic] debería pronunciarse sobre la aplicación de un precepto, y no sobre el precepto mismo. La única forma de operación posible, en términos lógicos, de este control, es que exista un acto de aplicación (idea congruente con la de un recurso en que lo que verdaderamente se está examinando es el actuar del órgano recurrido)" 62 .

Respecto del límite con las potestades de la judicatura ordinaria, se seńala también que el control concreto por parte del Tribunal Constitucional "implica grados diferentes de conocimiento de los jueces constitucionales acerca del asunto de fondo y, en cierto sentido, de 'invasión' o 'intromisión' en el mismo" 63 , lo cual no generará problemas en la medida que el control sea de carácter estricto y no se amplíe en demasía ${ }^{64}$.

Estas ideas llevan necesariamente a constatar la necesidad de precisar que en el sistema chileno ya "no solo el producto de la actividad del legislador estará sujeto a control de constitucionalidad, sino que también las resoluciones de los jueces y magistrados" 65 , en la medida que la única forma posible de aplicación de un precepto legal a un caso concreto pendiente de resolver ante un tribunal ordinario o especial es la dictación de resoluciones judiciales a su amparo, interpretando el precepto y subsumiendo en él los hechos litigio0sos, para, mediante dichas resoluciones judiciales, producir un determinado resultado que se traduce en resolver la gestión de determinada forma, lo que, si produce un resultado contrario a la Constitución será declarado inconstitucional de manera preventiva, antes de que ello ocurra, en sede de inaplicabilidad, o bien, si ya se produjo, en ciertos caso la sentencia de inaplicabilidad operará como "amparo imperfecto o cuasi amparo"66.

A modo ejemplar, y para entender los alcances de dicha configuración, resulta útil señalar que la diferenciación del control de normas (abstractos) y el aseguramiento de derechos mediante acciones de amparo (devenidas en controles concretos), en el caso espańol, se traduce en que las acciones para poner en movimiento la jurisdicción constitucional son diferentes (recurso y cuestión de inconstitucionalidad por un lado y amparo extraordinario por otra parte), con objetos y efectos diferentes, por lo que su diferenciación teórica y pedagógica resulta sencilla. Así, los controles de constitucionalidad de la ley son de orden abstracto (incluso en el caso de la cuestión de inconstitucionalidad, que, a pesar de contar con el elemento de incidentalidad, concluye como un examen netamente abs- 
tracto desprovisto de vinculaciones respecto del proceso litigioso, es decir, conforme a la terminología de Rolla, sería de carácter "fronterizo" ${ }^{67}$ ), en la medida que "el Tribunal se sitúa ya frente al control abstracto de la norma, desvinculado, al menos formalmente, del caso concreto en el que se suscitó la cuestión" 68 .

En dicho sistema, el control de actos de aplicación de normas por el juez se realiza en sede de amparo -y no de la abstracta cuestión de constitucionalidad-, por medio del cual lo que se declara inconstitucional es una o más resoluciones judiciales. En el caso de constatarse que la inconstitucionalidad está en la norma habilitante y no en el acto de aplicación, el Tribunal Constitucional español puede plantear de oficio la denominada "autocuestión" de constitucionalidad, es decir, además del amparo, de oficio realiza un examen abstracto de constitucionalidad de la ley habilitante. En el caso chileno nada de ello ocurre: el control de normas es primordialmente concreto y de estrictos efectos erga omnes, mediante la inaplicabilidad, y-como ya se viera- la denominada justicia constitucional de derechos fundamentales se encuentra radicada en los tribunales ordinarios.

\section{(3.3) ¿QUÉ ELEMENTOS DE CONTROL CONCRETO TIENE EL INSTITUTO DE LA INAPLICABILIDAD POR INCONSTITUCIONALIDAD DE LA LEY?}

De acuerdo a lo ya reseñado, para desentrañar el carácter concreto de la acción de inaplicabilidad, es menester recordar que la Constitución Política establece en su artículo $93 \mathrm{n}^{\circ} 6$ el control de inaplicabilidad dentro de las atribuciones del Tribunal Constitucional ${ }^{69}$.

Giancarlo Rolla denomina "fronterizo" al control de carácter incidental, pero finalmente abstracto. Rolla (2005) 279.

68 Pérez Tremps, Pablo (2005). "La cuestión de inconstitucionalidad en el derecho espańol". Estudios constitucionales, Ańo 3, No 1, p. 139. Aun cuando destaca que la necesaria conexión con el caso concreto, también Balaguer Callejón reconoce el carácter abstracto de este enjuiciamiento de constitucionalidad, ver Balaguer Callejón, Francisco et alii (2005). Derecho Constitucional, tomo II, Madrid: Tecnos, p. 240.

69 Solo para efectos metodológicos y de orden es necesario que se establece como atribución del Tribunal Constitucional "Resolver, por la mayoría de sus miembros en ejercicio, la inaplicabilidad de un precepto legal cuya aplicación en cualquier gestión que se siga ante un tribunal ordinario o especial, resulte contraria a la Constitución" y que, a su turno, el inciso $11 \mathrm{del}$ mismo artículo 93 seńala que "la cuestión podrá ser planteada por cualquiera de las partes o por el juez que conoce del asunto. Corresponderá a cualquiera de las salas del Tribunal declarar, sin ulterior recurso, la admisibilidad de la cuestión siempre que verifique la existencia de una gestión pendiente ante el tribunal ordinario o especial, que la aplicación del precepto legal impugnado pueda resultar decisivo en la resolución de un asunto, que la impugnación esté fundada razonablemente y se cumplan los demás requisitos que establezca la ley. A esta misma sala le corresponderá resolver la suspensión del procedimiento en que se ha originado la acción de inaplicabilidad por inconstitucionalidad". Del texto constitucional derivan una serie de características, a saber: 1) Es una competencia privativa y excluyente del Tribunal Constitucional; 2) Es una acción; 3) Tiene una pretensión específica: precisamente la petición es que no se 
¿Es la inaplicabilidad un control de carácter concreto claramente configurado?

¿O bien es solo un aparente control concreto que en realidad solo está dotado del elemento incidental y debiera ser calificado de "fronterizo"?

Más allá de lo seńalado por la doctrina nacional, que en forma casi unánime alude al carácter concreto de la inaplicabilidad tras la reforma del $2005^{70}$, la sola lectura de la normativa constitucional que contiene el estatuto de la inaplicabilidad permite señalar que:

(a) El elemento de incidentalidad concurre como presupuesto de admisibilidad, en la medida que debe verificarse "la existencia de una gestión pendiente ante el tribunal ordinario o especial', en la cual se produzca la cuestión de constitucionalidad, de manera que la inaplicabilidad no puede ser concebida como un recurso de carácter directo, sino como un control con claro carácter incidental, en la medida que se desarrolla en el marco de un proceso pendiente. En este sentido, la Ley No 17.997, Orgánica Constitucional del Tribunal Constitucional, dispone en su artículo 47 A que al requerimiento de inaplicabilidad debe acompańarse un certificado expedido por el tribunal que conoce del proceso a quo, estableciéndose así la forma específica de acreditar la existencia de la gestión y la relación del requirente con ella. Por mandato expreso de dicha norma, en el citado certificado debe darse cuenta de:

a.1) La existencia del proceso,

a.2) El estado en que se encuentra,

a.3) La calidad de parte del requirente y el nombre y domicilio de las partes y de sus apoderados.

aplique un precepto legal a una causa pendiente, que delimita lo que más adelante se especificará dentro de lo que el tribunal chileno ha llamado "competencia específica", principio enunciado por la Corte Constitucional italiana bajo el concepto de "respeto del principio de 'correspondencia entre lo demandado y lo resuelto"' en materia de control concreto. PizzoRusso (2006) 249; 5) Produce efectos inter partes; 6) Procede por vicios de constitucionalidad de fondo o de forma, como el Tribunal Constitucional lo ha señalado en la sentencia roles acumulados $\mathrm{N}^{\circ} 608,609,610,611,612$, entre otras, en orden a que "...resulta obvio que si en determinado caso la inaplicabilidad se acoge por estimarse que el precepto impugnado adolece de inconstitucionalidad de forma, disminuirá la importancia del caso concreto y la declaración de inaplicabilidad adquirirá una dimensión más general...”; 7) La sentencia que acoge el requerimiento obliga al Tribunal que resuelve la gestión pendiente a inaplicar el precepto legal impugnado, y a la inversa, la sentencia que desestima, no obliga al juez a aplicar el precepto impugnado, no porque tenga facultades de control difuso, sino porque la determinación de la legislación aplicable la hace el juez del fondo al resolver el asunto; como la inaplicabilidad es un control previo a la decisión, es posible que la norma impugnada, finalmente, no sea de aplicación al caso; 8) La legitimación activa corresponde al juez y a las partes de la gestión.

70 Ver los trabajos ya aludidos sobre el carácter concreto del control de inaplicabilidad, sin perjuicio de Aldunate Lizana (2007) y (2009). 
La misma norma exige, en el caso de requerimiento de inaplicabilidad planteado por el tribunal que conoce de la causa, que sea formulado por medio de un oficio, en el que deberán acompañarse copias de las piezas de mayor relevancia del expediente, indicando las partes y sus apoderados, debiendo dejar constancia en el proceso a quo de haberse requerido de inaplicabilidad.

Es del caso seńalar que en la situación de no acompañarse dichos antecedentes, la sanción establecida en el artículo $47 \mathrm{D}$ de dicho cuerpo legal es la inadmisión a trámite del requerimiento.

Por otra parte, el artículo $47 \mathrm{~F}$ de la citada ley orgánica, establece como causal de inadmisibilidad el que "no exista gestión judicial pendiente en tramitación, o se haya puesto término a ella por sentencia ejecutoriada".

b) La titularidad de la acción de inaplicabilidad corresponde al juez que conoce del asunto o a las partes del mismo, sin que el texto constitucional admita excepciones, además de tener efectos inter partes, lo que es plenamente concordante con su carácter concreto, ya que, en la medida que el caso concreto es relevante para el juicio, lo lógico será que la sentencia tenga efectos solo en el marco del juicio pendiente. Así, por la vía de la legitimación activa, la incidentalidad y los efectos el carácter subjetivo y particular de los intereses en cuestión está claramente configurado.

c) El elemento de relevancia concurre en la medida que es requerido, también como presupuesto de admisibilidad, "que la aplicación del precepto legal impugnado pueda resultar decisivo ${ }^{71}$ " en la resolución del asunto litigioso, pero el juicio de relevancia presenta caracteres totalmente diferentes al sistema italiano: en nuestro sistema, con iniciativa de parte y con iniciativa de oficio del juez, el juicio de relevancia es analizado y resuelto por una de las salas del TC -no por el Tribunal a quo-. El juicio de relevancia en Chile es así parte integrante del control de admisibilidad en el Tribunal Constitucional $-\mathrm{y}$ no una cuestión prejudicial, ventilada ante el tribunal ordinario,

71 En similares términos, el Tribunal Constitucional de Chile ha seńalado que "todo precepto legal que se impugne no constituye generalmente una norma aislada, sino que es un enunciado que, puesto en aplicación, guarda relaciones de interdependencia y operatividad con otros, a la luz de los cuales cabe ser interpretado y aplicado". Tribunal Constitucional dE Chile. Sentencia de 13 de mayo de 2008. Rol No 993-07. Requerimiento de inaplicabilidad presentado por Paul Morrison Cristi respecto del artículo $4^{\circ}$ de la Ley No 20.000 , en la causa RIT No 073/2007 RUC 070000159-4, del Tribunal de Juicio oral en lo Penal de Temuco. De tal forma que es deber de dicho Tribunal "evitar que el precepto legal impugnado se interprete y aplique de un modo en que efectivamente produzca un efecto contrario a la Constitución". Tribunal Constitucional de Chile. Sentencia de 11 de diciembre de 2007. Rol No 80607. "Requerimiento de inaplicabilidad presentado por Inmobiliaria PY S.A. respecto del artículo 416, inciso tercero, del Código Procesal Penal". Disponible en http://www.tribunalconstitucional.cl/index.php/sentencias/view/12 [Fecha de visita: 23 de noviembre de 2009]. 
como en Italia-, debiendo constatar la sala -en específico- que el precepto impugnado puede resultar "de aplicación decisiva" en la resolución de la gestión pendiente invocada, lo que se comprende en tanto que el órgano jurisdiccional a quo, llamado a aplicar la norma impugnada, necesariamente debe decidir sobre el derecho de las partes en dicho juicio y dentro de las hipótesis de aplicación de la norma cuestionada, de lo cual se deriva la incidencia directa del precepto impugnado según su aptitud o ineptitud para producir su aplicación un resultado específico diferente del que se generaría con su inaplicación. Este aspecto o característica de "relevancia", sin que se le denomine de esa forma, está recogida como presupuesto de admisibilidad en la acción de inaplicabilidad, existiendo abundante jurisprudencia sobre su significado en tanto tal ${ }^{72}$.

(d) El caso particular constituye un marco y, al mismo tiempo, parte del parámetro de juzgamiento, en la medida que la aplicación del precepto debe producir un resultado contrario a la Constitución dentro del proceso a quo, lo que solo podrá ocurrir en el marco de dictación de resoluciones judiciales en el mismo, lo traslada gran parte del examen de constitucionalidad al acto de aplicación y/o a sus efectos,

En sede de admisibilidad, y sin aludir la conceptualización dogmática del juicio de relevancia, se ha examinado lo "relevante" del precepto impugnado en la resolución de la gestión pendiente que se invoca, habiéndose declarado que si se está en presencia de una "materia en la cual el precepto impugnado no tiene incidencia", carece de la aptitud "de producir un efecto contrario a la Constitución Politica en los términos que lo exige su articulo $93 N^{\circ} 6 \mathrm{e}$ inciso undécimo". Trubunal Constitucional de Chile. Sentencia de 18 de diciembre de 2008. Rol No 1280-08. "Requerimiento de inaplicabilidad deducido por Humberto Piemonte Miani respecto del artículo 45, incisos primero y segundo, de la Ley de Quiebras, contenidos en el Libro IV del Código de Comercio". Disponible en http://www.tribunalconstitucional.cl/index.php/sentencias/view/1073 [fecha de visita 23 de noviembre de 2009]. Por otra parte, hay que tener presente que, para cumplir este presupuesto de admisibilidad, la aplicación del precepto debe encontrarse pendiente o - a lo menos- no agotada. En este sentido, se ha razonado que el requerimiento de inaplicabilidad es inadmisible cuando "la declaración de inaplicabilidad solicitada por la requirente ya no puede tener efecto alguno en el estado procesal en que actualmente se encuentra el proceso (...) puesto que las normas impugnadas ya recibieron aplicación". Tribunal Constitucional de Chile. Sentencia de 13 de octubre de 2008. Rol No 1235-08. "Requerimiento de inaplicabilidad de Inmobiliarias Los Jazmines S.A. respecto de los incisos primero y segundo del artículo 45 del Libro IV del Código de Comercio". Disponible en http://www.tribunalconstitucional.cl/index.php/sentencias/view/1029 [Fecha de visita: 23 de noviembre de 2009]. En el mismo sentido, entre otras, roles 915 a 985, de 24 de enero de 2008. Acerca de la relevancia ha razonado también el Tribunal Constitucional que se "debe determinar si el precepto legal impugnado puede recibir aplicación en la gestión pendiente, si la misma es decisiva y, a continuación, si ello produce efectos contrarios a la Carta Fundamental'. 'Tribunal Constitucional de Chile. Sentencia de 12 de julio de 2007. Rol No 596-06. "Requerimiento de inaplicabilidad por inconstitucionalidad presentado por el diputado Iván Paredes Fierro, respecto del inciso tercero del artículo 416 del Código Procesal Penal". Disponible en http://www.tribunalconstitucional. $\mathrm{cl} /$ index.php/sentencias/view/106 [Fecha de visita: 23 de noviembre de 2009], doctrina que es reiterada, en orden a que "resulta necesario examinar si la aplicación del precepto legal que se impugna ha de producir un resultado distinto al que se generaria al inaplicarla, y si, en caso 
constituyendo entonces un "control de aplicación de preceptos", en el cual concurre la doble relación del objeto controlado con el caso concreto al tener que evaluar si la aplicación en el caso concreto produce o no un resultado inconstitucional.

e) En lo relativo a la variante del control concreto, estamos en presencia de una versión con caracteres propios del sistema europeo, que, en principio, distingue el juzgamiento del litigio de fondo del juzgamiento de la cuestión de constitucionalidad, en la medida que el artículo 76 de la Constitución atribuye el conocimiento y resolución de las causas civiles y criminales a los tribunales ordinarios y su artículo 93 confiere al Tribunal Constitucional las potestades de control de constitucionalidad ${ }^{73}$.

\section{(3.4) LA DEFINICIÓN DEL CARÁCTER CONCRETO DEL CONTROL DE INAPLICABILIDAD EN LA DOCTRINA NACIONAL}

Para finalizar, a título ilustrativo, se hace necesario revisar qué ha entendido la doctrina por el carácter concreto de la inaplicabilidad en nuestro medio. A pesar de haber bastantes escritos acerca de temas relativos a control de normas, tras la reforma de 2005 la conceptualización del carácter concreto del control de inaplicabilidad es incipiente e insuficiente: hay pocos textos que se atrevan a ello, destacando los de autores como Gastón Gómez, Arturo Fermandois, Manuel Núnez, Lautaro Ríos, Francisco Zúńiga y el ya citado trabajo de Eduardo Aldunate. En dichos estudios se resalta alguna característica propia del instituto de inaplicabilidad

afirmativo, dicho resultado es o no contrario a la Constitución Politica". Tribunal Constitucional de Chile. Sentencia de 30 de octubre de 2007. Rol No 767-07. "Requerimiento de inaplicabilidad presentado por Guillermo Arroyo Aguirre respecto del artículo $1^{\circ}$ de la Ley $\mathrm{N}^{\circ}$ 18.865". Disponible en http://www.tribunalconstitucional.cl/index.php/sentencias/busca_avanzado [Fecha de visita: 23 de noviembre de 2009].

73 Sin perjuicio de la abundante jurisprudencia de admisibilidad acerca de requerimientos destinados a revisar de manera directa resoluciones judiciales, la diferenciación de ambos juzgamientos ha sido declarada expresamente por el propio tribunal de control de constitucionalidad, razonando que "no corresponde a esta Magistratura ponderar las probanzas del juicio pendiente", tampoco "establecer el alcance y límite del supuesto de hecho que motiva la aplicación de una norma infraconstitucional, lo que es propio de los jueces del fondo, sino que está llamada, por via de requerimiento, a evitar la aplicación de preceptos legales que puedan producir efectos inconstitucionales". Tribunal Constitucional de Chile. Sentencia de 24 de abril de 2007. Rol No 1006-07. "Requerimiento de inaplicabilidad de Eduardo Berríos Novakovic respecto del artículo 96 del Código Tributario", considerando 12 del voto de rechazo. Disponible en http://www.tribunalconstitucional.cl/index.php/sentencias/view/1090 [Fecha de visita: 23 de noviembre de 2009]. En el considerando $13^{\circ}$ del voto de rechazo en la misma sentencia, el Tribunal Constitucional señala categóricamente que "no puede emitir un pronunciamiento valorativo sobre hechos litigiosos de la gestión pendiente, cuyo establecimiento pareciera ser clave para la resolución del asunto. Cabe señalar que la ponderación de los mismos corresponde a los jueces del fondo, por ser también un tema de legalidad ordinario y estar dentro de su competencia relativa a la gestión, no correspondiendo que esta Magistratura los pondere". 
o se busca subsumirla en algún elemento propio del control concreto y en algún caso se busca construir definiciones genéricas y sistemáticas del concepto de control concreto.

Gastón Gómez, a propósito del objeto del control concreto de inaplicabilidad, a partir de la reforma constitucional de 2005, señala que el mismo no es el enunciado normativo en sí, sino que "en realidad, es la o las interpretaciones o significados de ese enunciado que el juez o la parte consideran inconstitucional en la específica aplicación de dicha norma al caso" 74 , a partir de lo cual la inaplicabilidad emergería como un medio de control de constitucionalidad negativo de interpretaciones judiciales, en tanto permite descartar variantes hermenéuticas que a juicio del Tribunal Constitucional pugnen con la Constitución.

En un sentido que también descarta el examen de constitucionalidad del precepto legal de manera aislada, Fermandois seńala que el control de inaplicabilidad "se centra entonces en las circunstancias de hecho que originan la gestión pendiente, de manera que pueden estas circunstancias de hecho atenuar o agravar la inconstitucionalidad"75. Así, para este autor, el objeto de este control concreto estaría dado no por la norma -o al menos no por sí sola- ni tampoco por la interpretación de la misma, sino por la ponderación de los hechos litigiosos a los cuales se va aplicar el precepto en cuestión, y en segundo término, la aplicación de la normativa legal a ellos, elemento que se puede concluir a partir de su afirmación de que la acción de inaplicabilidad, en tanto control concreto, "es un llamado al Tribunal Constitucional a ponderar la arbitrariedad en la aplicación de la norma respectiva" 76 . A partir de esta conceptualización, se concluiría por dicho autor que Tribunal Constitucional estaría facultado para "apreciar, evaluar y enjuiciar la razonabilidad o arbitrariedad con que la norma legal ha sido aplicada en el caso concreto" 77 .

También, en una vertiente que fluye desde la igualdad en la aplicación de la ley, pero en base a la jurisprudencia del propio Tribunal Constitucional, Manuel Núñez ha seńalado que en el control concreto

Gómez Bernales (2005) 670.

FERMANDOIS (2008) 176.

Fermandois (2008) 176.

FERMANDoIs (2008) 177. En esta vertiente, es menester precisar que en el marco de la relación de potestades del Tribunal Constitucional y del Poder Judicial en la Constitución, se entrega el control de constitucionalidad de aplicación de preceptos en gestiones pendientes al Tribunal Constitucional y el control de validez de resoluciones judiciales a los tribunales ordinarios, por lo que el "ponderar la arbitrariedad en la aplicación de la norma" exige establecer claramente el parámetro de juzgamiento, diferenciar cuestiones de legalidad y cuestiones de constitucionalidad y también la inaplicabilidad de la casación y de la nulidad procesal, sobre todo teniendo en cuenta que la gestión judicial en que incide la inaplicabilidad debe encontrarse pendiente. Si todas estas precisiones no son tenidas en cuenta es fácil transformar la inaplicabilidad en una instancia adicional y anómala, en una verdadera invasión de potestades del poder judicial. 
de inaplicabilidad, el examen del resultado contrario a la Constitución "surge, no del enunciado de la norma, sino de su aplicación a un caso concreto "78, de manera que el caso sub lite cobra relevancia, en términos que "la centralidad del caso concreto significa que el juicio de inaplicabilidad no puede prescindir del análisis puntual de la "relación jurídica procesal" en que aquel incide" 79 o decidir al margen "de los antecedentes que proporciona la gestión en el que el precepto legal cuestionado pude aplicarse" 80 . Esto último vale incluso cuando se trata de normas cuyo enunciado evidencia una contradicción ostensible con la Constitución ${ }^{81} 82$.

De lo expuesto por Núńez, cabría seńalar que el elemento de mayor importancia en el juicio concreto de inaplicabilidad se encuentra en lo que llamamos la doble relación del caso y, en específico, en las consecuencias de la aplicación de la norma al caso concreto.

Pero la enunciación más clara y usada del control concreto es elaborada en el marco de la significación de los cambios del año 2005 al control de inaplicabilidad por inconstitucionalidad, en tanto ha pasado a ser en sentido puro la versión chilena del control concreto. Así, en un texto profusamente citado por la jurisprudencia del Tribunal Constitucional, el profesor Lautaro Ríos sostiene, centrado, al igual que Núnez, en la doble relación del caso, que "la inaplicabilidad cumple la función de impedir que la parte que la invoca en el caso concreto del que conoce un tribunal, se vea afectada por un precepto legal cuya aplicación a ese caso particular resulte evidentemente contraria a la Constitución y, especialmente, a los fines perseguidos por ésta" 83 , lo que deriva en que debe ser evaluado no solo el precepto legal, sino que también su aplicación al caso específico y los resultados que produzca, por lo que "en este instituto procesal -además del juez y de las partes- comparecen tres elementos de cotejo necesarios para su decisión, a saber: la norma constitucional, el precepto legal cuya inaplicación se solicita y -lo más específicamente decisivo- el examen particular acerca de si, en ese caso, la aplicación del precepto

Tribunal Constitucional de Chile. Sentencia de 11 de diciembre de 2007. Rol No 80607 , considerando 32 .

79 NúŃEZ PoBlete (2008) 130.

80 Tribunal Constitucional de Chile. Sentencia de 30 de octubre de 2007. Rol No 767-07.

81 "El riesgo de ser declarado inadmisible aconseja la mayor concreción del cuestionamiento de constitucionalidad. Por otra parte, la existencia de enunciados per se inconstitucionales, y la consecuente reducción de la relevancia del caso concreto, solo ha sido sugerida últimamente por el Tribunal: "[E]s forzoso que siempre el conflicto sometido a su decisión consista en la existencia de una contradicción concreta y determinada entre la ley y la Constitución la cual en algunas ocasiones podrá brotar con claridad del solo texto del precepto legal cuestionado y en otras ocasiones emergerá de las peculiaridades del caso concreto sub lite, (STC rol núm. 810-07, 24 de enero de 2008)". NúŃnez Poblete (2008) 130.
}

82 NúŃEZ Poblete (2008) 131.

83 Ríos Álvarez, Lautaro (2005 a) 77. 
cuestionado pudiera generar efectos opuestos a la finalidad implícita de aquella" 84 .

El control concreto de inaplicabilidad conceptuado por Lautaro Ríos claramente implica un juicio de coherencia entre la norma constitucional, la norma legal y los efectos de la aplicación del precepto legal. En tanto se refiere a la "finalidad implícita" de la norma constitucional que se invoque, implica un concepto amplio de Constitución, que incluye su texto, principios, reglas y valores, además de lo cual "obliga a prestar atención a la particularidad del caso concreto en que la acción se interpone, en lugar de prescindir de la especialidad del caso y de los efectos lesivos de la aplicación de la norma, como ocurrió frecuentemente en la jurisprudencia de la Excma. Corte Suprema" ${ }^{15}$. Esta definición es la más usada en la jurisprudencia del Tribunal Constitucional y sobre esta vertiente ha fluido de manera constante, a partir de la sentencia rol 478, de 8 de agosto de 2006. En un sentido similar, Francisco Zúńiga plantea que el carácter concreto del control de inaplicabilidad viene planteado porque "los aspectos de hecho de la gestión judicial en que incide resultan claves para construir el juicio de legitimidad constitucional de la norma legal impugnada" 86 y porque la vulneración a la Constitución "debe resultar de la aplicación del precepto legal impugnado al asunto específico en que se constituye en derecho material aplicable" 87 .

Es necesario también destacar que entre los elementos particulares derivados de la configuración del sistema de control en Chile -control concreto sin amparo-, la inaplicabilidad es un examen de aplicación previo, pues opera antes que el precepto se aplique, en la medida que se exige por la propia Constitución que la gestión en que incide la norma controlada esté pendiente de resolver.

A lo antes expuesto, cabe señalar que la configuración del juicio de relevancia como presupuesto de admisibilidad, más la necesidad de no estar concluido en juicio a quo, impide evaluar, por regla general, los actos derivados de la aplicación pretérita de preceptos, salvo que la misma aún no se hubiere agotado, como ocurriría, por ejemplo, en el caso de encontrarse la gestión pendiente concluida, pero con recursos, por ejemplo de apelación o casación, pendientes de resolver ${ }^{88}$, en la medida que:

a) De la aplicación de precepto impugnado dependa el resultado de ellos, a partir de lo cual, aun cuando hubieren empezado a operar di-

Ríos Álvarez (2005a) 77.

Ríos Álvarez (2005) 639.

ZúŃIGA URBINA / Vega MÉndez (2006) 149.

ZÚNiga URBINA / Vega MéndeZ (2006) 153.

$\mathrm{O}$ bien sea una cuestión administrativa con recursos jurisdiccionales pendientes. 
chos preceptos en la gestión, dicha aplicación no se hubiere agotado aún por no haber sentencia de término y

b) Que lo que se encuentre pendiente esté determinado por el juicio de relevancia, caso en el cual la inaplicabilidad por inconstitucionalidad podría devenir en lo que llamamos un cuasi amparo o amparo imperfecto $^{89}$.

\section{CONCLUSIONES}

1) La introducción del control concreto en Europa lleva a que su definición en función de la judicial review sea insuficiente e incompleta en el contexto de sistemas jurídicos con Tribunales Constitucionales de matriz kelseniana o concentrada.

2) La introducción del control concreto tras la segunda posguerra en los sistemas concentrados europeos genera la distinción entre dos desarrollos diferentes: el binomio concreto-difuso y el binomio concretoconcentrado.

3) Por lo anterior, la configuración del control concreto admite dos variantes claramente distinguibles: la norteamericana y la europea, que se diferencian por separar la segunda el juicio de constitucionalidad del juicio de la cuestión de fondo, que en la variante americana son una sola cosa.

4) El control concreto se define por los siguientes elementos mínimos, comunes a sus dos variantes: incidentalidad, subjetividad del derecho litigioso en el caso concreto, examen de relevancia y la doble relación del caso concreto con el control, lo que amplía su objeto desde la norma hacia a los actos de aplicación de ella.

5) En el marco de la variante concreto-concentrado, el control puede realizarse antes o después del acto de aplicación, de lo cual derivará su configuración como amparo o como cuestión de constitucionalidad de normas.

6) El carácter concreto del control de inaplicabilidad deriva de contar todos los elementos mínimos de concreción: incidentalidad, relevancia y doble relación del caso, además de ser claramente un control de aplicación.

7) El juicio de relevancia se encuentra consagrado como requisito de admisibilidad y es realizado por las Salas del Tribunal Constitucional al resolver acerca de la admisibilidad.

8) El elemento de doble relación se encuentra presente al exigirse que la aplicación del precepto impugnado produzca un efecto contrario a la

89 CAzor / PiCA (2009). Es posible citar como ejemplos de este fenómeno, entre otras, las sentencias roles 944,781 y 815 . 
Constitución en el caso específico, lo que obliga a evaluarlo en tanto relación jurídica litigiosa e incorporar dicho examen al proceso de control.

9) Dentro de los elementos secundarios o variables del control concreto, la inaplicabilidad tiene efectos inter partes, se efectúa antes de ser dictada la sentencia de término el proceso en el que incide y, por otra parte, limita en las potestades de la judicatura ordinaria. Dicho límite no es claro y deberá ser establecido tanto por la doctrina como por la jurisprudencia.

10) La notoria indefinición de dicho límite abre el espacio para que, por la vía de la evolución hacia amparo imperfecto, el control de inaplicabilidad pueda evolucionar como un medio de revisión indirecto de resoluciones judiciales.

\section{BIBLIOGRAFÍA}

- Aldunate Lizana, Eduardo (2007). "La reforma constitucional del año 2005 desde la teoría del Derecho y la teoría de la Constitución”. Revista de Derecho Público No 69, tomo I, pp. 35-57.

go: Legal Publishing.

(2009). Jurisprudencia constitucional 2006-2008, Santia-

- Aviña Martínez, Rogelio (2009). "El control previo en el Derecho constitucional local: un visor a la ley de justicia constitucional local para el Estado de Coahuila de Zaragoza", en Gámiz Parral, Máximo N. Astudillo, César Santos Olivo, Isidro de los: Derecho constitucional estatal. Memorias del VI y VII Congresos Estatales de Derecho Constitucional de los estados, México: UNAM.

- Balaguer Callejón, Francisco et alii (2005). Derecho Constitucional, tomo II, Madrid: Tecnos.

- Bertelsen, Raúl (1969). Control de constitucionalidad de la ley, Santiago: Editorial Jurídica de Chile.

- Bon, Pierre (1992). "La protección constitucional de los derechos fundamentales: aspectos de Derecho comparado europeo". Revista del Centro de Estudios Constitucionales, No 11.

- Bordalí Salamanca, Andrés (2006). "La tutela de los derechos fundamentales", en él mismo (coordinador): Justicia constitucional y derechos fundamentales, Santiago: LexisNexis.

- Brage Camazano, Joaquín (2009). La acción de inconstitucionalidad, México: UNAM.

- Carrillo, Marc (2001). "La jurisdicción constitucional española y el caso chileno". Revista de Derecho (Valdivia), vol. 12, No 1 pp. 7589. Disponible en http://mingaonline.uach.cl/scielo.php?script=sci_ arttext\&pid $=$ S0718-9502001000100005\&lng=es\&nrm =iso

[Fecha de visita: 30 Julio 2009]. 
- Cazor Aliste, Kamel / Pica Flores, Rodrigo (2009). "Tribunal Constitucional y control concreto en Chile: jevolución hacia un amparo imperfecto?". Revista General de Derecho Constitucional Iustel, No 7.

- De Cabo Martín, Carlos (2000). Sobre el concepto de ley, Madrid: Trotta.

- De Vega García, Pedro (2005). "La eficacia frente a particulares de los Derechos Fundamentales (La problemática de la Drittwirkung der Grundrechte)", en Luis Aguiar de Luque (coordinador): Constitución, estado de las autonomías y justicia constitucional, libro de homenaje al profesor Gumersindo Trujillo, Valencia: Tirant lo Blanch, pp. 801-822.

- Fermandois V., Arturo (2008). "Inaplicabilidad y control concreto del Tribunal Constitucional: enjuiciando la arbitrariedad en la aplicación de la ley". Actualidad Jurídica, $\mathrm{N}^{\circ} 17$.

- Fernández Segado, Francisco (2002). "La jurisdicción constitucional ante el siglo XXI (La quiebra de la bipolaridad "sistema americano-sistema europeo-kelseniano" y la búsqueda de nuevas variables explicativas de los sistemas de control de constitucionalidad)". Disponible en http://www.acader.unc.edu.ar/artjurisdiccionconstitucional.pdf [Fecha de visita: 18 de julio de 2009].

- García de Enterría, Eduardo (1991). La Constitución como norma y el Tribunal Constitucional, Madrid: Civitas.

- Gómez Bernales, Gastón (2005). "La reforma constitucional a la jurisdicción constitucional”, en Zúńiga Urbina, Francisco (coordinador). Reforma constitucional, Santiago: LexisNexis.

- Garretón, Manuel Antonio (1995). Hacia una nueva politica. Estudios sobre las democratizaciones, México: Fondo de Cultura Económica.

(1990). "La posibilidad democrática en Chile", en Democracia contemporánea: Transición y Consolidación, pp. 177-190, Santiago: Editorial Universidad Católica de Chile.

- Hormazábal Malarée, Hernán (2008). El nuevo Tribunal Constitucional, Santiago: Legal Publishing.

- Mendizábal Allende, Rafael (2005). "La guerra de los jueces: Tribunal Supremo vs Tribunal Constitucional”. Revista de Derecho Procesal No 1, pp. 489-536.

- Moreira Cardoso da Costa, José Manuel (2002). "Tópicos sobre competencias e integración del Tribunal Constitucional de Portugal", Ius et Praxis, vol. 8, $\mathrm{N}^{\circ} 1$, Universidad de Talca, Chile, disponible en http://www.scielo.cl/scielo.php?pid=S071800122002000100017\&script=sci_arttext [Fecha de visita: 22 de julio de 2009].

- Nogueira Alcalá, Humberto (2003). “Tópicos sobre jurisdicción constitucional y tribunales constitucionales". Revista de Derecho (Val- 
divia), vol.14 [citado 22 julio 2009], p. 43-66. Disponible en http:// mingaonline.uach.cl/scielo.php?script $=$ sci_arttext \&pid=S07189502003000100003\&lng=es\&nrm=iso [Fecha de visita: 22 de julio de 2009].

- Nogueira Alcalá, Humberto (2002). "La reforma constitucional a la jurisdicción constitucional: del doble control concentrado de constitucionalidad a la concentración del control en el Tribunal Constitucional". Ius et Praxis, año 8, $\mathrm{N}^{\circ} 1$, pp. 337370. Disponible en http://www.scielo.cl/scielo.php?pid=S071800122002000100019\&script=sci_arttext [Fecha de visita: 22 de julio de 2009].

- Núñez Poblete, Manuel Antonio (2008). "El control de la igualdad en la aplicación de la ley como factor de expansión del control concreto de constitucionalidad de las leyes", en AA. VV.: Sentencias destacadas 2007, Santiago: Instituto Libertad y Desarrollo.

- Pérez Tremps, Pablo (2005). "La cuestión de inconstitucionalidad en el derecho español". Estudios constitucionales, Año 3, No 1.

- Pizzorusso, Alessandro et alii. (1981). "Garanzie Costituzionalli" en G. Branca (coord.), Comentario della constituzione, Bologna-Roma: Zanichelli-Il Foro italiano.

(2005). "Los sistemas de justicia constitucional: de los modelos a la praxis", en él mismo: Justicia, Constitución y Pluralismo, Lima: Palestra.

(2006). "La justicia constitucional italiana, entre modelo difuso y modelo concreto", en Requejo Pagés, Juan Luis (coordinador): Fundamentos, cuadernos monográficos de Teoría del Estado, Derecho Público e Historia constitucional, $\mathrm{N}^{\circ} 4$ de la serie: La rebelión de las Leyes: Demos y nomos: la agonía de la justicia constitucional", Oviedo: Junta General del Principado de Asturias.

- Ríos Álvarez, Lautaro (2005). "El nuevo Tribunal Constitucional", en Francisco Zúniga Urbina (coordinador). Reforma constitucional, Santiago: LexisNexis.

(2005 a). "Trascendencia de la reforma constitucional en la fisonomía y las atribuciones del Tribunal Constitucional". Estudios Constitucionales, Ańo 3, $\mathrm{N}^{\circ}$. 1, Ediciones Universidad de Talca.

- Rolla, Giancarlo (2005). "Juicio de legitimidad constitucional y tutela de los derechos fundamentales", Revista Iberoamericana de Derecho Procesal Constitucional, No. 3, pp. 271-291. Disponible en http://www.iidpc.org/revistas [Fecha de visita: 14 de julio de 2009].

- Rubio Llorente, Francisco (1997). "La interpretación constitucional", en él mismo: La Forma del Poder, estudios sobre la Constitución, Madrid: Centro de Estudios Políticos y Constitucionales.

(1998). "Tendencias actuales de la Jurisdicción Constitucional en Europa”, en Rubio Llorente, Francisco y Jiménez Campo, 
Javier (coords.): Estudios sobre Jurisdicción Constitucional, Madrid: McGraw-Hill.

- Ruiz Tagle, Pablo, (1999). "Control constitucional concentrado y difuso: el uso de una dicotomía ruinosa". Revista de Derecho Público, No 61, pp. 81-95.

- Starck, Christian (2002). "Derechos fundamentales y derecho privado". Revista Española de Derecho Constitucional, Año 22, No 66.

- Troncoso, Antonio (2001). "Las sentencias básicas del Tribunal Constitucional”. Revista Española de Derecho Constitucional, Año 21, No 61.

- Vírgala Foruria, Eduardo (2001). "Control abstracto y recurso directo de inconstitucionalidad en los Estados Unidos". Revista Española de Derecho Constitucional, Ańo 21, No 62, pp. 77-124.

- Zapata Larraín, Patricio (2006). "Las sentencias atípicas en la jurisprudencia del Tribunal Constitucional chileno". Estudios constitucionales, Ańo 4, No 2, pp. 175-187.

- Zúñiga Urbina, Francisco (2006). "Refundación del Tribunal Constitucional", La Semana Jurídica, del 19 al 26 de junio, Santiago: LexisNexis.

- Zúñiga Urbina, Francisco Vega Méndez, Francisco (2006). “El nuevo recurso de inaplicabilidad por inconstitucionalidad ante el Tribunal Constitucional. Teoría y práctica”. Estudios Constitucionales, Año $4, \mathrm{~N}^{\circ} 2$.

\section{JURISPRUDENCIA}

- Tribunal Constitucional de Chile. Sentencia de 24 de abril de 2007. Rol No 1006-07. "Requerimiento de inaplicabilidad de Eduardo Berríos Novakovic respecto del artículo 96 del Código Tributario", considerando 12 del voto de rechazo. Disponible en http:// www.tribunalconstitucional.cl/index.php/sentencias/view/1090 [Fecha de visita: 23 de noviembre de 2009].

- Tribunal Constitucional de Chile. Sentencia de 12 de julio de 2007. Rol No 596-06. "Requerimiento de inaplicabilidad por inconstitucionalidad presentado por el diputado Iván Paredes Fierro, respecto del inciso tercero del artículo 416 del Código Procesal Penal". Disponible en http://www.tribunalconstitucional.cl/index.php/ sentencias/view/106 [Fecha de visita: 23 de noviembre de 2009].

- Tribunal Constitucional de Chile. Sentencia de 30 de octubre de 2007. Rol No 767-07. "Requerimiento de inaplicabilidad presentado por Guillermo Arroyo Aguirre respecto del artículo $1^{\circ}$ de la Ley $\mathrm{N}^{\circ} 18.865^{\prime}$. Disponible en http://www.tribunalconstitucional. $\mathrm{cl} /$ index.php/sentencias/busca_avanzado [Fecha de visita: 23 de noviembre de 2009]. 
- Tribunal Constitucional de Chile. Sentencia de 13 de mayo de 2008. Rol No 993-07 "Requerimiento de inaplicabilidad presentado por Paul Morrison Cristi, respecto del artículo $4^{\circ}$ de la Ley $\mathrm{N}^{\circ}$ 20.000", considerando 5. Disponible en http://www.tribunalconstitucional.cl/index.php/sentencias/view/934 [Fecha de visita 23 de noviembre de 2009].

- Tribunal Constitucional de Chile. Sentencia de 13 de octubre de 2008. Rol No 1235-08. "Requerimiento de inaplicabilidad de Inmobiliarias Los Jazmines S.A. respecto de los incisos primero y segundo del artículo 45 del Libro IV del Código de Comercio”. Disponible en http://www.tribunalconstitucional.cl/index.php/sentencias/view/1029 [Fecha de visita: 23 de noviembre de 2009].

- Tribunal Constitucional de Chile. Sentencia de 18 de diciembre de 2008. Rol No 1280-08. "Requerimiento de inaplicabilidad deducido por Humberto Piemonte Miani respecto del artículo 45, incisos primero y segundo, de la Ley de Quiebras, contenidos en el Libro IV del Código de Comercio". Disponible en http://www. tribunalconstitucional.cl/index.php/sentencias/view/1073 [fecha de visita 23 de noviembre de 2009].

- Tribunal Constitucional de Chile. Sentencia de 22 de enero de 2009. Rol No 1006-07 "Requerimiento de inaplicabilidad de Eduardo Berríos Novakovic respecto del artículo 96 del Código Tributario" (cons. 11 del voto de rechazo). Disponible en línea en http:// www.tribunalconstitucional.cl/index.php/sentencias/view/1090 [Fecha de visita 23 de noviembre de 2009].

- Tribunal Constitucional de Chile. Sentencia de 10 de marzo de 2009. Rol No 1202-08 "Requerimiento de inaplicabilidad de Hinrichsen Trading S.A. respecto del artículo 45, incisos primero y segundo, del Título IV "De la Declaración de Quiebra”, del Código de Comercio, y del artículo 26, inciso segundo, del Decreto Ley $\mathrm{N}^{\circ}$ 3.475, Ley de Timbres y Estampillas", considenrando 9. Disponible en http://www.tribunalconstitucional.cl/index.php/sentencias/ view/1106 [Fecha de visita: 23 de noviembre de 2009]. 